\title{
Clinical Stage IVA Gastric Cancer AJCC v8
}

National Cancer Institute

\section{Source}

National Cancer Institute. Clinical Stage IVA Gastric Cancer A/CC v8. NCI Thesaurus. Code C133652.

Stage IVA includes: (T 4b, Any N, M0): T4b: Tumor invades adjacent structures/organs. M0: No distant metastasis. (AJCC 8th ed.) 